\title{
Editorial
}

\section{Revista Estudos Feministas: 1992-2002, a primeira década}

Este é o sétimo número da Revista Estudos Feministas lançado após sua instalação na Universidade Federal de Santa Catarina, em 1999, e o décimo nono desde seu lançamento na Universidade Federal do Rio de Janeiro, em 1992. Dadas as instabilidades que costumam cercar os processos de produção editorial de modo geral - muitas das quais extrapolam o plano diretamente relacionado ao financiamento -, a garantia da periodicidade ao longo dessa primeira década nos leva a atribuir a este número um significado especial.

Nesse intervalo de dez anos, muitas coisas aconteceram. Em 1992, ano em que foi lançado o célebre 'número zero' da Revista, editado por Lena Lavinas e Valéria Lamego, e com a coordenação editorial de Ana Arruda Callado, o país enfrentava sérias turbulências políticas: o pronunciamento de Pedro Collor, publicado na revista Veja em 10 de maio de 1992, fazia sérias acusações de corrupção ao governo do seu irmão Fernando Collor, então presidente da República. Essas denúncias, junto com uma série de outras suspeitas, além do descontentamento popular com a política econômica do governo, impulsionaram a criação de uma Comissão Parlamentar de Inquérito. Sob um clima de emoção, instabilidade, tensões e inúmeros conflitos, os trabalhos da Comissão, respaldados pela massiva mobilização da sociedade civil, terminaram por indicar o impeachment do presidente.

Votado no Congresso Nacional em 29 de setembro de 1992, o impeachment foi aprovado por uma expressiva maioria de votos (441 votos a favor, 38 contra e uma abstenção). Durante os meses de maio a setembro de 1992, organizações sindicais, estudantis, instâncias de deliberação coletiva vinculadas às demandas feministas, aos ambientalistas, aos trabalhadores sem terra, além de outros segmentos, juntaram-se e/ou alternaram-se em uma série de eventos, ocupando espaços públicos em clima de jovial transversalidade, para registrar seu repúdio à corrupção e sua frustração com o resultado da primeira eleição democrática no país após os longos anos de ditadura militar. $O$ resultado foi surpreendente para o Brasil e para o mundo: embora relutante, Collor renunciou $e$, em dezembro de 1992, assumiu o governo o vice-presidente ltamar Franco. 
No plano internacional, entre outros fatos também importantes, dissolvia-se a União das Repúblicas Socialistas Soviéticas, Bill Clinton vencia as eleições presidenciais nos Estados Unidos e, na África do Sul, um plebiscito, com aprovação de 69 por cento dos eleitores, punha fim ao regime de apartheid. Definitivamente, a história testemunha que 1992 não foi um ano qualquer.

Atenta às turbulências, e consciente do potencial da prática e da política feminista, a Revista Estudos Feministas destaca, no seu número zero, temas caros ao movimento das mulheres e aos estudos de gênero: análise da luta das mulheres na área da Teologia; estudo da metáfora da irmandade e suas ressonâncias ao longo da história; questionamentos sobre a interseção entre gênero, raça e geração entre trabalhadoras domésticas na constituição de uma identidade de classe; um "estudo sem importância" (segundo sua autora) da entrada da escritora Raquel de Queirós na Academia Brasileira de Letras e, conseqüentemente, no cânone literário brasileiro; um ensaio relembrando, com extrema sensibilidade, os ensinamentos de Elizabeth Lobo e suas significativas contribuições ao feminismo; e um balanço dos dez anos de lutas pela legalização e descriminalização do aborto. O primeiro dossiê da Revista Estudos Feministas dedicava espaço para uma discussão das relações entre mulher e meio ambiente, em fina sintonia com os ruídos da ECO-92.

Dez anos depois, o presente número está sendo lançado em meio a uma conjuntura internacional estremecida pelos impactos de pelo menos três grandes acontecimentos: os atentados terroristas de 11 de setembro às torres gêmeas em Nova York e ao Pentágono; a (in)conseqüente e polêmica reação do governo norte-americano, conhecida como "guerra contra o terrorismo"; e o recrudescimento da dimensão étnica e religiosa de alguns conflitos mundiais, particularmente entre árabes e judeus.

No plano nacional, os principais gestores do país continuam estimulando as privatizações, deixam sem resposta uma série de reivindicações populares e restringem os investimentos na área social. A sociedade civil se mobiliza em torno da eleição presidencial, com um crescente contingente de mulheres se envolvendo, direta ou indiretamente, nos processos eleitorais. Multiplicam-se as organizações nãogovernamentais feministas, os núcleos de pesquisa nas Academias e as publicações feministas, tanto aquelas provenientes das ONGs como as acadêmicas.

Buscando, mais uma vez, a sintonia com o contexto histórico e político, a editoria da Revista Estudos Feministas estruturou este número em torno de um eixo central que tem ocupado boa parte do noticiário internacional e local: a questão da discriminação e do preconceito. Assim, os artigos 
e os depoimentos do Dossiê, organizado por Luiza Bairros, registram e analisam a participação das mulheres afrobrasileiras, afro-latino-americanas e indígenas no processo da III Conferência Mundial contra o Racismo, Discriminação Racial, Xenofobia e Intolerâncias Correlatas, realizada em Durban, África do Sul, entre 31 de agosto e 7 de setembro de 2001.

A seção Artigos, fiel ao eixo temático proposto pelo Dossiê, inicia-se com a instigante discussão de Maria Bernardete Ramos sobre as idéias que dominavam a intelectualidade brasileira nos anos 1920/1940, destacando aquelas ligadas à eugenia. Estabelecendo uma relação entre Adalzira Bittencourt e Monteiro Lobato, o texto associa a primeira ao movimento modernista e critica a ênfase do modernismo na maternidade enquanto missão da mulher no projeto de higienização da sociedade.

Sarah Grussing Abdel-Moneim, falando do "ciborgue zapatista", discute as implicações teóricas do papel da tecnologia na configuração discursiva e nas representações sobre a resistência indígena em Chiapas (México), refletindo sobre as complexas relações entre um segmento de camponeses pobres e rebeldes e as possibilidades de resistência abertas pelo mundo virtual da comunicação em rede entre povos e nações.

Lúcia Helena de Azevedo Vilela faz uma leitura, à luz das teorias feministas e de uma perspectiva pós-moderna, de Almanac of the Dead, da escritora Leslie Marmon Silko, salientando o uso que a autora dá aos conceitos marxistas de tempo e história e enfatizando "a percepção indígena do tempo como eternos presentes, que é também resistência à opressão, uma vez que o passado não é jamais esquecido".

Neste número também decidimos publicar a tradução em português de um artigo antológico da pioneira e já falecida crítica literária negra Barbara Christian. Em "A disputa pela teoria" ("The Race for Theory"), Christian faz uma crítica às tendências e disputas em torno da teoria na crítica literária, em geral, e na feminista, em particular. Argumenta que o/a crítico/a torna-se cada vez mais um/a acadêmico/a, para quem lecionar ou escrever sobre trabalhos específicos de literatura são atividades que ficam subordinadas a um impulso primordial, o momento em que se cria uma teoria, fixando-se por um determinado tempo um conjunto de idéias, o qual será substituído nos meses seguintes por alguma outra teoria que entrará na disputa. Christian mostra que os/as escritores/as de cor sempre teorizaram - mas de forma bastante diferente do modelo ocidental de lógica abstrata.

Ella Shohat, a partir de diversos registros culturais, de suas memórias familiares dos constantes deslocamentos migratórios pós-coloniais (registrados em fotografias familiares) e de instalações da artista Lynne Yamamoto - em uma das 
quais utiliza um longo feixe de cabelos negros artificiais pendurado em um velho torcedor de roupa, tirado de uma antiga máquina de lavar -, faz reflexões poéticas e contundentes sobre identidades culturais hifenizadas, 'viajando' entre diferentes continentes e gêneros de escrita para estabelecer um diálogo entre geografias e histórias comumente separadas.

A seção Ensaios incorpora duas contribuições também afinadas com o eixo deste número. O texto de Lourdes Bandeira e Analía Soria Batista caracteriza o preconceito e a discriminação como formas de violência mobilizadas contra a diferença, estabelecendo, a partir de ampla revisão bibliográfica, as distinções entre as sutilezas, a provisoriedade e a capilaridade do preconceito e o caráter segregacionista, violento e mais definitivo da discriminação. Sônia Weidner Maluf, por sua vez, levantando importantes questões a respeito da personagem travesti Agrado, no filme Tudo sobre minha mãe, do cineasta espanhol Pedro Almodóvar, discute a noção de corporalidade e da construção do sujeito, dialogando sobretudo com as teorias do corpo da etnologia ameríndia brasileira. O ensaio busca propor alguns elementos para uma reflexão sobre a importância da análise de experiências de margem na renovação teórica no campo dos estudos feministas e de gênero.

O tema do corpo, da corporalidade e da abjeção é também aqui explorado em uma memorável entrevista de Judith Butler, na qual ela discute e esclarece alguns dos conceitos-chave que fundamentam sua teorização do gênero.

As resenhas deste número se dedicam a avaliar e divulgar livros mais recentes sobre temas como mulheres e sustentabilidade na Amazônia; identidade de gênero, pessoa e memória; nacionalidade literária como identidade; crítica feminista ao conceito de identidade no contexto do póscolonialismo; cultura física e comportamento; novas tecnologias reprodutivas; a questão do dote e a condição das mulheres no Brasil; gênero e violência.

Além da menção aos dez anos da Revista Estudos Feministas e de uma síntese do perfil do presente número, alguns fatos importantes sobre a editoria da revista devem ser apontados. Desde que se instalou na Universidade Federal de Santa Catarina, em 1999, a editoria da revista tem passado por algumas reestruturações, objetivando ampliar sua base institucional, distribuir de modo mais equânime as inúmeras atribuições que caracterizam as etapas da produção editorial e assegurar um maior equilíbrio entre as diferentes áreas disciplinares envolvidas com a revista. O volume 7, n. 1/2 (1999), o volume 8, n. 1 e n. 2 (2000), bem como o volume 9, n. 1 (2001), foram editados por Claudia de Lima Costa e Miriam Pillar Grossi, tendo-se consolidado uma parceria entre o Centro 
de Filosofia de Ciências Humanas e o Centro de Comunicação e Expressão da UFSC. Essa parceria se refletiu tanto na estruturação do Comitê Editorial Executivo quanto na do Comitê Editorial Nacional. Considerando-se a conveniência de um rodízio na editoria a cada dois anos, iniciou-se a preparação da transição dessas duas editoras, com a incorporação de Luzinete Simões Minella à editoria do v. 9, n. 2, em junho de 2001. Foi também criada uma editoria de resenhas, a cargo de Cristina Scheibe Wolff. Em março do corrente ano, Miriam Pillar Grossi deixou a editoria e passou a ser editora adjunta. Claudia de Lima Costa ocupará função idêntica a partir de agosto de 2002. Com o volume 10, número 2 (2002), a Revista Estudos Feministas contará com nova editoria de artigos, composta por Joana Maria Pedro, Luzinete Simões Minella, Simone Pereira Schmidt e Susana Bornéo Funck.

Essa redefinição, bem como uma consciência maior sobre o montante de responsabilidade e de trabalho implicado na realização de cada número da Revista, impulsionou a discussão, aprovação e implementação de um novo modelo editorial, que incorpora a contribuição da maioria das integrantes do antigo Comitê Editorial Executivo nas diferentes seções da revista, conforme poderá ser verificado a partir do volume 10, número 2 (2002). As atividades relacionadas com a coordenação editorial serão desempenhadas por Luzinete Simões Minella. Compreendemos que, como qualquer iniciativa de natureza editorial, esse novo modelo será testado na prática, podendo ser submetido a futuras reestruturações, sempre e quando consideradas necessárias e úteis para a Revista.

Simultaneamente a essas mudanças, comunicamos às/ aos nossas/os leitoras/es que um projeto para a implementação da versão eletrônica da Revista Estudos Feministas, combinado com a criação de um portal de publicações feministas e de um consórcio de publicações feministas, foi elaborado e encaminhado à Fundação Ford. Recentemente aprovado e em plena fase de implantação, esperamos já neste ano termos o presente número da Revista também disponível on-line, com acesso restrito a nossas/os assinantes. Esclarecemos desde já que a implantação da REF On-line não substituirá a distribuição de sua versão impressa e que nossas/os assinantes terão a seu dispor as duas modalidades. A implementação do Consórcio de Revistas Feministas, por sua vez, terá como ponto de partida a realização do I Encontro Brasileiro de Publicações Feministas, nos dias 7, 8 e 9 de agosto próximo, em Florianópolis, do qual resultará também um Dossiê, e do II Encontro Brasileiro e I Encontro Internacional de Publicações Feministas, previsto para o segundo semestre de 2003.

Para concluir com outras boas notícias, queremos assinalar que a Revista Estudos Feministas ganhou dois novos indexadores: Scientific Library Online/SciELO e International 
Bibliography of the Social Sciences/IBSS (London School of Economics, Inglaterra).

Ressaltamos ainda que a Revista esteve presente na maior parte dos eventos ligados à área durante os primeiros meses de 2002, destacando-se o Fórum Social Mundial (Programação da REDEFEM), a Conferência Nacional de Mulheres Brasileiras, a XXIII Reunião Brasileira de Antropologia, - XVII Encontro Nacional da Associação Nacional de PósGraduação e Pesquisa em Letras e Lingüística (ANPOLL), o VIII Encontro da Associação Brasileira de Literatura Comparada (ABRALIC), além do XV Congresso Mundial de Sociologia, realizado em Brisbane, na Austrália. Está prevista a presença da Revista nos seguintes eventos: III Encontro Internacional dos Estudos Feministas de Língua Francesa ("Ruptures, Résistences et Utopies"), a ser realizado no mês de setembro de 2002 em Toulouse; XXVI Encontro Anual da Associação Nacional de Pesquisa e Pós-Graduação em Ciências Sociais (ANPOCS); XI Encontro Anual da Rede Feminista Norte e Nordeste de Estudos e Pesquisas sobre a Mulher e Relações de Gênero (REDOR), entre outros eventos.

Agradecemos a todas/os as/os colaboradoras/es que encaminharam seus textos para apreciação e às pareceristas ad hoc pelas críticas e sugestões para o aprimoramento das idéias apresentadas neste exemplar. Manifestamos nosso reconhecimento, primeiro, a toda a equipe da Revista, sem cujo apoio teria sido impossível concluir este número; segundo, ao Programa de Auxílio Editoração do CNPq, por ter possibilitado os recursos materiais necessários à garantia da periodicidade da Revista; terceiro, à Fundação Ford, pela liberação de recursos para implementação do já citado projeto, que permitirá a expansão do público da Revista e sua vinculação a uma rede de publicações feministas; e, quarto, às/aos nossas/ os assinantes, por terem firmado um compromisso com a Revista, dando-lhe estímulo à sua continuidade. Nossos especiais agradecimentos a Sonia E. Alvarez, membro do Conselho Editorial Internacional, pelo desmedido e inestimável apoio durante todos esses anos da Revista na UFSC.

Ao senador Abdias do Nascimento agradecemos a generosa autorização para uso de sua gravura na capa deste número.

Claudia de Lima Costa Luzinete Simões Minela 